\title{
O AVESSO DO AVESSO conjuntura e estrutura na recente agenda política brasileira
}

\author{
Cláudio Gonçalves Couto \\ Professor do Departamento de Política da PUC-SP. \\ Autor do livro O desafio de ser governo: o PT na Prefeitura de São Paulo
}

\begin{abstract}
Resumo: Fernando Henrique Cardoso implementou sua agenda governamental utilizando, simultânea e articuladamente, diversos mecanismos decisórios. Destacam-se as medidas provisórias e as emendas constitucionais. Converteram-se umas - concebidas para emergências conjunturais - em instrumentos legislativos corriqueiros, por isso mesmo estruturais; e outras - feitas para modificar a estrutura institucional perene de nosso sistema político - em instrumentos de implementação das políticas particulares de um governo particular, por isso mesmo conjunturais.

Palavras-chave: teoria constitucional; processo decisório; sistema de governo.
\end{abstract}

$\mathrm{O}$ governo Fernando Henrique Cardoso foi muitas vezes acusado de governar por medidas provisórias. Notabilizou-se, por outro lado, pela realização de profundas reformas no modelo econômico e no Estado brasileiro, quase todas implementadas por meio de emendas constitucionais.

Um e outro desses instrumentos decisórios de que lançou mão o governo contrastam pelos distintíssimos graus de exigência para sua aprovação. Enquanto as MPs requerem quase unicamente a ação do presidente, as emendas constitucionais demandam a costura de amplo consenso nas duas Casas do Congresso e entre elas. O que marcou afinal este governo? O decretismo desenfreado ou as negociações extenuantes visando à construção de amplíssimas coalizões? De certa forma, talvez ambas as coisas, imbricadamente.

Qual o significado da utilização articulada desses mecanismos no processo de implementação de políticas governamentais? No que essa utilização afeta o funcionamento da democracia brasileira? Que condições políticas se fazem necessárias para viabilizar, simultaneamente, uma agenda de reformas constitucionais e outra implementada por meio de medidas provisórias? São estes alguns dos temas discutidos aqui.

Após algumas considerações de ordem teórica, passarei à análise do uso desses dispositivos pelo governo Fernando Henrique Cardoso.

\section{ESCOPO DO PODER E CONTROLES}

A delegação de poder (e a conseqüente definição de seu escopo) passa, na tradição contratualista liberal, pelo estabelecimento de dois pactos: um entre os indivíduos fundadores do Estado, pelo qual este é criado e são definidos seus atributos $-o$ pacto constitucional propriamente dito. Outro entre governantes e governados (posterior, portanto, ao pacto originário), pelo qual os últimos definem as atribuições específicas daqueles a que delegam poder e até que ponto esses podem (e devem) ir no exercício da delegação, cuja definição está subordinada às condições fixadas pelo primeiro pacto. O primeiro é o pacto constituinte da pólis, ao passo que o segundo é o pacto que ocorre já no âmbito da pólis constituída; noutras palavras, o primeiro pacto institui um Estado (e, conseqüentemente, uma coletividade, a nação), enquanto o segundo institui um governo - confere mandatos a um indivíduo ou a um corpo de indivíduos que serão responsáveis pela produção de políticas e pela administração do Estado.

Os governados transferem poder a agentes cujas decisões deverão acatar; o poder de mando dos governantes provém, portanto, de uma delegação dos governados. Como controlar os mandatários, para que ajam dentro dos limites desejados? Solução óbvia das democracias é a criação de mecanismos verticais de controle dos governados sobre os governantes, reduzindo a assimetria de poder 
existente entre ambos (Held, 1991:146), evitando o abuso por parte dos últimos - nos termos de Sartori (1994:28990), reduzindo o risco decorrente da própria separação entre governantes e governados.

Sartori aponta que todo processo decisório envolve (a) custos internos, de tomada das decisões para aqueles que decidem e (b) riscos externos, para os destinatários das decisões. Diferentemente dos custos, mais facilmente determináveis ao menos ex post, riscos são indeterminações ex ante, "um tipo particular de incerteza, qual seja, uma potencialidade percebida em sua periculosidade. É de perder (não de ganhar) que se fala quando se trata de risco". O desafio da democracia (ou de qualquer sistema de decisões coletivizadas) é "aumentar a probabilidade de 'resultados satisfatórios' e minimizar a probabilidade de “resultados danosos"”. São dois os riscos da ação estatal: "principalmente riscos de opressão, mas também (...) riscos decorrentes da incompetência, estupidez ou interesses sinistros" (Sartori, 1994: 289-90). ${ }^{1}$

O mais notório mecanismo de redução do risco é a eleição. Sujeitos a eleições periódicas, os governantes se veriam obrigados a agir minimamente de acordo com a vontade dos governados - seja ela uma vontade a priori, anterior à eleição, ou a posteriori, forjada no processo governamental $^{2}$ - e visando às eleições subseqüentes, buscando convencer os governados/eleitores da justeza de decisões não previstas à época da eleição; por ela, governados definem eficazmente seus governantes e, menos eficazmente, suas políticas. ${ }^{3}$

É importante também o acordo constitucional estabelecido, definindo não só a relação entre governados e determinados governantes (pela eleição), mas igualmente estruturando a relação entre os cidadãos, destes com seus governantes (sejam quais forem eles e as preferências do eleitorado em qualquer conjuntura) $)^{4}$ e dos vários governantes entre si. É a própria constituição - forma geral de organização da vida política numa sociedade - que definirá como os governados controlam eleitoralmente os governantes e como se controlam uns governantes pelos outros. Em suma, o acordo constitucional estabelece as condições do exercício do poder, define as obrigações governamentais e os recursos para os governantes se desincumbirem delas. Ao mesmo tempo, estipula o que lhes é vedado: por omissão, não incorporando ao seu rol de atribuições certos assuntos, ou por proibição, interditando ao governo certas questões.

Para os Federalistas, ao definir o que caberia ao governo fazer, quais seus poderes, nada que não lhe tivesse sido explicitamente atribuído poderia ser invocado como prerrogativa. Dessa forma, as garantias individuais seriam asseguradas pelo fato de que o governo teria um poder limitado no nascedouro; não teria como usurpar as liberdades individuais, uma vez que o alcance de seu poder estaria limitado desde a estipulação. Para os Antifederalistas, os governos tendem a utilizar todo o poder possível, sendo necessário definir assim quais são os direitos e garantias individuais, fixando claramente os limites além dos quais o governo não poderia avançar: tudo que não fosse vedado ao governante lhe seria permitido. Noutras palavras, no primeiro caso os limites são definidos positivamente - pelo alcance da delegação; no segundo, eles são definidos negativamente - pela estipulação de restrições ao poder governamental.

Ambas as concepções foram previstas pela Constituição dos Estados Unidos: a dos Federalistas no texto base, aprovado na Convenção de Filadélfia e a dos Antifederalistas nas dez primeiras emendas, a Bill of Rights. Dificilmente um ordenamento constitucional democrático contemplará, exclusivamente, uma só concepção de estruturação do arcabouço estatal. Conflitos que naturalmente permeiam o jogo político da conformação institucional dos Estados nacionais são resolvidos por negociação e acomodação dos interesses e dos entendimentos concretamente existentes em cada caso histórico, de acordo com as regras de elaboração constitucional vigentes. Assim, a introdução de princípios contrapostos pode ser resultado de compromissos que privilegiam a factibilidade política, não a consistência teórica.

Além da relação vertical entre governantes e governados e dos limites existentes entre ambos, na conformação de um governo limitado porém eficaz, devem-se estipular as relações horizontais entre diferentes atores governamentais. Define-se algo central no ordenamento constitucional: a forma pela qual o governo decide. Decorre daí a teoria da separação dos poderes: governo limitado não é somente o que recebe uma delegação popular limitada, ostensivamente restringida, devendo prestar contas periodicamente ao povo; é também um governo cujas diferentes partes têm poderes restritos para o desempenho de funções específicas, por si sós insuficientes à ação governamental em sua plenitude. Esta apenas se efetiva pela conjugação das diferentes funções. Pela divisão pura e simples de tarefas entre os atores governamentais anulase o poder de um ator num dado âmbito, delegando-se as atribuições desse âmbito a outro, se necessário mediante interdições explícitas. A isso agrega-se um sistema de 
controles reciprocos (checks and balances) entre atores governamentais, partilhando uns de poderes dos outros, requerendo acordos visando concretizar não apenas o processo governamental em sua plenitude, mas até mesmo as próprias tarefas específicas de cada ramo de governo. É precisa a síntese de Pessanha (1998:246-7) a respeito: “... no caso da separação de poderes, trata-se de uma divisão em três ramos distintos, cada qual limitado à sua esfera específica e sem interferências sobre a função dos demais. Cada ramo deve ser composto por membros diferentes, não sendo permitida a participação em mais de um ramo ao mesmo tempo. No caso dos freios e contrapesos, cada ramo tem o poder de exercer um grau de controle direto sobre os outros poderes, pela permissão para exercer uma pequena e limitada parte de suas funções".

A questão do controle recíproco entre os Poderes se articula a outra: a hierarquia decisória. Certas decisões, dado seu peso no processo governamental, exigem maior acordo entre os atores políticos. Exemplo disso é a exigência de um trâmite que se dê não apenas no interior de uma ou outra das instâncias estatais, mas que passe por várias delas; ou ainda, a exigência de quóruns qualificados para a aprovação de determinadas matérias no Parlamento, requerendo o acordo de grupos que doutra forma não teriam importância para o processo decisório. Quanto maior a importância potencial de uma decisão e os efeitos possíveis dela sobre os atores envolvidos, mais complexo seu trâmite, requerendo mais negociação e mais discussão - inclusive num maior número de instâncias antes que se conclua a deliberação, gerando enfim uma decisão de governo.

\section{PROCESSO DE GOVERNO E HIERARQUIA DECISÓRIA}

Nem todas as decisões estatais têm o mesmo estatuto, seja por sua importância à própria operação do Estado, seja pela maior complexidade do processo formal de tomada de decisões. O primeiro aspecto refere-se ao alcance das decisões tomadas. Algumas delas acabam por condicionar as demais, tanto ao definir as regras segundo as quais outras decisões deverão ser tomadas (Buchanan e Tullock, 1999), como ao estipular limites para o conteúdo das próximas decisões. Na medida em que definem qual a estrutura do aparato estatal, isto é, como este se constitui, são o que poderíamos chamar de decisões constitucionais. Conformando as regras básicas de operação do aparato estatal, as decisões constitucionais dão forma à organização política propriamente dita, à politéia - ou, para utilizar o termo inglês, de uso mais corrente, à polity. É a estrutura constitucional do Estado, a polity, que define as condições do jogo político propriamente dito (a politics). A constituição compreende o conjunto das regras do jogo, mas não define em princípio os resultados do jogo, as decisões políticas tomadas (as policies). Estas decorrem do desfecho de conflitos, negociações e acordos, travados entre os participantes dos diversos âmbitos decisórios da polity.

Para Buchanan e Tullock (1999), são constitucionais as regras de tomada de decisões. Segundo os autores, elas definem a forma pela qual se tomarão as decisões válidas para uma coletividade. A escolha constitucional é a escolha dessas regras e decorre de um cálculo visando à combinação de dois objetivos. O primeiro é a redução dos custos esperados das decisões coletivas, para o que requer-se o aumento do número dos que devem acatar as decisões. Quanto maior esse número, maior o acordo necessário e, por conseguinte, menores os custos esperados de futuras decisões cujo conteúdo se ignora de antemão. Na medida em que o tamanho do grupo necessário à decisão aumenta, cresce a probabilidade de que se torne crucial a concordância de cada indivíduo que possa ser atingido por ela. Essa lógica alcança seu limite sob a regra da unanimidade, já que nesse caso cada indivíduo pode vetar toda e qualquer decisão que lhe desagrade, reduzindo a zero o custo externo que a mesma possivelmente lhe acarretaria. O segundo objetivo é a redução dos custos do processo decisório. Quanto maior o número necessário à aprovação de qualquer decisão, maiores os custos do processo, pois aumenta o poder de barganha de qualquer indivíduo relativamente aos demais. Quanto menor esse número, menor o poder de barganha dos indivíduos considerados isoladamente: não havendo a concordância de um, pode-se obter a anuência de outro em seu lugar, tornando-se mais fácil (e menos custoso) decidir. À redução do custo da tomada de decisão, todavia, corresponde um incremento do custo esperado da decisão propriamente dita. Como diria Sartori (1994), há um aumento dos riscos das virtuais decisões a serem tomadas.

Polity, politics e policies correspondem, portanto, a diferentes níveis da vida estatal. O primeiro, à sua estrutura; o segundo, ao seu funcionamento; o terceiro, aos seus produtos. A estrutura diz respeito às regras de relacionamento entre os atores e às organizações em que eles atuam - ou às instituições propriamente ditas. $\mathrm{O}$ funcionamento tem a ver com a atividade política, que se desenrolaria de 
uma forma ou de outra, fossem quais fossem as instituições vigentes, muito embora as condições desse desenrolar variassem consideravelmente, dependendo do tipo de arranjo constitucional em vigor. Os produtos são aquilo que o Estado gera, seja para se autogerir e manter-se, seja para responder às demandas sociais existentes - filtradas e interpretadas de acordo com as condições em que se desenrola a politics. A princípio, temos aí uma gradação em termos do que condiciona o quê: as regras institucionais condicionam o jogo político, que condiciona o conteúdo das políticas.

A influência das policies sobre a politics é provável num sistema político marcado por elevados graus de competitividade e permeabilidade das elites políticas às demandas sociais, como o sistema poliárquico. A competição é aberta, quaisquer decisões compatíveis com os princípios constitucionais são válidas, todos os atores políticos podem legitimamente encaminhar as mais variadas demandas e o que será ou não levado a cabo define-se na própria competição (Dahl, 1997). Improvável é a modificação da polity pela policy. Mudanças nas regras constitucionais são, em principio, decorrência da percepção por parte dos atores políticos da existência de condições institucionais inadequadas para o desenrolar da politics, e não fruto do descontentamento com o conteúdo das policies. Se estas se mostram insatisfatórias para os jogadores em decorrência de debilidades do arcabouço constitucional, isto se dá antes por ele não permitir um processo decisório adequado do que por influências diretas da polity sobre as policies. Numa poliarquia, portanto, o arcabouço constitucional tende a ser muito mais estável do que o jogo político e do que a produção de políticas, uma vez que apenas define a forma como a politics ocorrerá; esta, por seu turno, é que definirá como se produzirão policies. Num sistema competitivo é mesmo desejável para os atores a estabilidade do arcabouço constitucional, pois regras estáveis reduzem o grau de incerteza em relação ao desenrolar do jogo, reduzindo assim a incerteza que cerca a produção de políticas. A estabilidade das regras é condição de segurança no jogo competitivo, pois permite saber que a própria competição será respeitada, não se transformando perdedores em ganhadores ou vice-versa, não privando subitamente de sentido estratégias estabelecidas, etc. ${ }^{5}$

Para que a estabilidade das regras constitucionais se torne algo provável, porém, duas condições devem estar presentes. Primeiro, a generalidade: regras constitucionais devem ser genéricas; caso contrário, mais do que parametrizar processos elas passam a definir resultados. Segundo, a inércia: regras constitucionais devem ser de difícil alteração; caso contrário, perdem seu caráter constitucional, tornando-se objeto de apreciação corriqueira. A obtenção da primeira condição é auto-evidente e se efetiva na própria confecção da regra: não se pode descer a detalhes, sob o risco de deixar-se de formular parâmetros gerais de funcionamento do Estado para criar-se instrumentos de administração de particularidades. Já a obtenção da segunda condição apresenta requisitos externos às próprias regras constitucionais (talvez possamos até mesmo falar em regras metaconstitucionais neste caso): são necessárias exigências severas para que elas sejam modificadas, já que regras difíceis de mudar tendem a ser estáveis, isto é, inertes.

Deve haver, portanto, correspondência entre o estatuto da norma e a complexidade do trâmite necessário à sua transformação; isso é algo que diz respeito não só às normas constitucionais, mas também a todo o corpo normativo do Estado. Quanto mais importante uma medida, maior a complexidade do processo de sua confecção e maior a necessidade de um consenso amplo entre os atores políticos participantes das instâncias decisórias para que essa medida seja expedida. Por isso, Buchanan e Tullock (1999) apontam que as decisões sobre regras constitucionais são aquelas às quais, mais do que a quaisquer outras, pode-se aplicar a regra da unanimidade.

Idealmente, a maior facilidade para a tomada de decisões nos diversos níveis infraconstitucionais se deve ao fato de que aquilo que se decide e implementa aí corresponde não à polity, mas às policies. Enquanto a polity diz respeito à estrutura da operação do aparato estatal, a policy diz respeito à sua operação de conjuntura. Podemos ainda dizer que decisões relativas à polity são decisões de caráter soberano, ao passo de que decisões relativas a policies são decisões de caráter governamental.

À luz desse pressuposto, quanto mais conjuntural uma decisão (mesmo em suas implicações), mais simples devem ser as condições para que seja tomada, de modo que ao imediatismo dos problemas que a suscitam corresponda a celeridade do processo. É bom que fique claro o significado dado a conjuntura nesta discussão: é definida por contraposição à noção de estrutura. Não se trata apenas do curto prazo, mas também do curto alcance: decisões conjunturais são circunstanciais; sua implementação não permite alterar a estrutura do Estado e, quanto menos se aproximam dessa possibilidade, mais conjunturais são. Noutros termos, são mais decisões de governo e menos 
decisões soberanas; trata-se mais de decisões de caráter ordinário e menos de caráter constitucional. O Quadro 1 resume essas distinções.

\section{QUADRO 1}

Natureza das Dimensões Ideais do Processo Político-Democrático

\begin{tabular}{|c|c|c|c|c|}
\hline Dimensão & Natureza & Denominação & $\begin{array}{c}\text { Característica } \\
\text { Formal }\end{array}$ & $\begin{array}{c}\text { Característica } \\
\text { Substantiva }\end{array}$ \\
\hline $\begin{array}{l}\text { Normatividade } \\
\text { Constitucional }\end{array}$ & $\begin{array}{c}\text { Regras Gerais } \\
\text { do Jogo Político } \\
\text { (Estrutura) }\end{array}$ & Polity & $\begin{array}{c}\text { Pacto entre os } \\
\text { diversos atores } \\
\text { políticos }\end{array}$ & Generalidade \\
\hline $\begin{array}{l}\text { Embates e } \\
\text { Coalizões Políticas }\end{array}$ & Jogo Político & Politics & $\begin{array}{l}\text { Relacionamento } \\
\text { dinâmico entre os } \\
\text { atores políticos }\end{array}$ & $\begin{array}{l}\text { Conflito e/ou } \\
\text { Cooperação }\end{array}$ \\
\hline $\begin{array}{l}\text { Normatividade } \\
\text { Governamental }\end{array}$ & $\begin{array}{l}\text { Resultados do } \\
\text { Jogo Político } \\
\text { (Conjuntura) }\end{array}$ & Policy & $\begin{array}{c}\text { Vitória/Derrota de } \\
\text { diferentes atores } \\
\text { políticos }\end{array}$ & Especificidade \\
\hline
\end{tabular}

Decisões no âmbito de um pacto constitucional jamais devem ser impostas, mas sempre acordadas entre todos os atores - idealmente de forma unânime. No mundo real a unanimidade é quase sempre impossível, de modo que as constituições procuram obedecer a regras menos exigentes para sua formulação e modificação - freqüentemente maiorias qualificadas. É no campo das policies que se dá o perde-ganha típico da política democrática, obviamente circunscrito em seu alcance pelo que foi definido no pacto constitucional. Por conseguinte, nesse âmbito é natural ocorrerem imposições ao invés de pactos; o papel impositivo cabe aos grupos ocasionalmente majoritários, dotados do poder de decidir à revelia da vontade das minorias. A normatividade constitucional é aqui a garantia de que esse procedimento não se converta em "tirania da maioria", seja formalmente pela estipulação de regras decisórias, que garantam a grupos minoritários maior peso em certas decisões sobre policies, seja substantivamente pela introdução no texto constitucional de limites para certas policies, que ficariam assim (como no primeiro caso) resguardadas pelas regras decisórias mais exigentes do processo de emendar disposição constitucional. ${ }^{6}$

Quanto mais se aumentam essas garantias, mais se aguça o consociativismo do sistema, reforçando a necessidade de negociação e elevando a possibilidade do veto a certas iniciativas. Quanto mais se restringem essas garantias, formal ou substantivamente, mais se caminha no sentido in- verso, incrementando-se o majoritarismo do sistema, reforçando o potencial de decisão. Para Tsebelis (1997), a excessiva "estabilidade das políticas" pode provocar a crise do regime, se o conduzir a uma paralisia decisória: a estabilidade perigosa aqui é a das policies, não a da polity. Com efeito, a estabilidade da polity é mesmo uma condição favorável à preservação do regime, como já foi apontado.

Como policies são decisões de caráter governamental propriamente dito, a noção de governabilidade - tantas vezes repudiada como autoritária - faz sentido se entendida como capacidade para a produção de policies e não para a mudança da polity. Assim, o campo por excelência da eficácia é o da produção de policies e o campo do controle (dos limites) é o da estruturação da polity. É claro que para dizer o que é efetivamente policy ou polity, numa dada realidade nacional, é preciso ter em vista a sociedade de que se trata. Uma questão irrelevante do ponto de vista constitucional num caso, pode assumir imensa importância noutro. Daí a pertinência da observação de Lijphart (1989), de que sistemas consociativos adequamse a países socialmente heterogêneos, quando o consociativismo encontra correspondência nessa heterogeneidade. ${ }^{7}$ Igualmente, mecanismos que exijam maior consociativismo - maior negociação - fazem sentido para decisões mais próximas do plano constitucional. Maior eficácia decisória - maior majoritarismo -, por sua vez, é tanto mais normal quanto mais as decisões estejam no âmbito da administração conjuntural dos negócios do governo. ${ }^{8}$

\section{FIGURA 1}

Representação Sintética da Relação entre Controle Democrático e Hierarquia Decisória

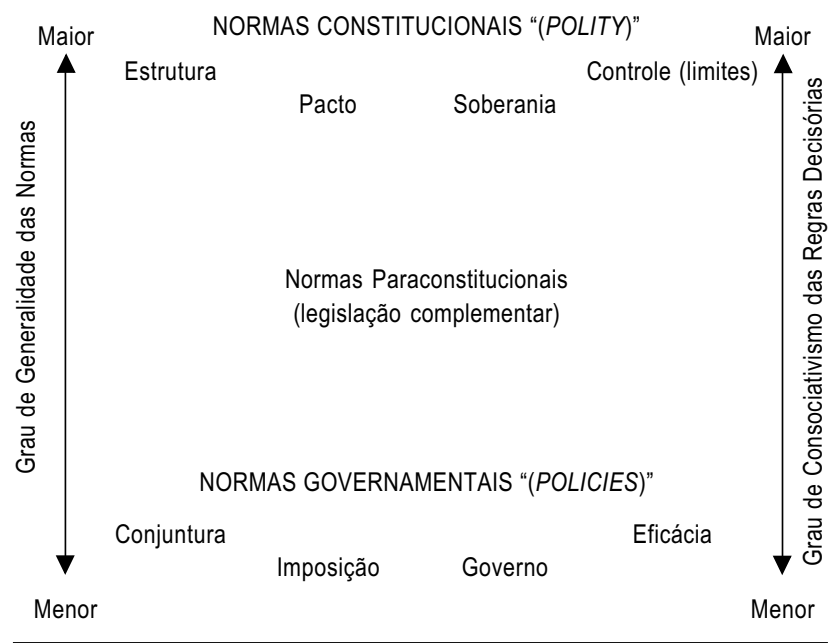


Trata-se do tema no plano ideal. O que acaba por ser efetivamente transformado em norma constitucional ou em norma ordinária depende da vontade dos constituintes, e dos conflitos que travam entre si. Trata-se de uma escolha política, feita nalgum momento histórico, afetando a estruturação do Estado, o desenrolar do jogo político e a tomada de decisões de governo e/ou administrativas. Temas tipicamente constitucionais podem ser remetidos ao arbítrio dos burocratas ou à vontade oscilante de maiorias parlamentares ocasionais; inversamente, temas tipicamente conjunturais - cuja mudança espera-se que correspondam à alternância dos partidos e lideranças no governo - podem transformar-se em letra constitucional, ganhando perenidade muito maior do que sugeriria seu alcance real, limitando a latitude decisória de futuros governantes. No primeiro caso, a conseqüência provável é a grande instabilidade das regras do jogo político; no segundo, a maior dificuldade governativa dos eleitos.

\section{FHC: GOVERNO CONSTITUINTE, GOVERNO POR DECRETO}

O primeiro mandato de Fernando Henrique Cardoso notabilizou-se pela realização de reformas estruturais do Estado e do capitalismo brasileiro. FHC aprofundou o que iniciara Fernando Collor de Mello, deflagrador da abertura comercial e das privatizações, intensificadas por Itamar Franco, também responsável pelo Plano Real, bemsucedida política de estabilização monetária. Cardoso implantou políticas que já se verificavam noutros países (Whitehead, 1993; Haggard e Kaufman, 1993), inclusive da América Latina, onde as reformas vinham sendo implementadas há tempos e o Brasil não era senão um retardatário (Almeida, 1996; Sallum e Kugelmas, 1993).

A agenda reformista de FHC contava, no entanto, com uma peculiaridade, comparada à de seus colegas latinoamericanos: implementar muitos de seus pontos importantes requeria reformar a Constituição (Couto, 1996; 1997; 1998a e b). A Carta aprovada em 1988 constitucionalizou questões da ordem econômica, da administração pública e do funcionamento previdenciário contrariamente aos planos do novo presidente e à tendência mundial hegemônica nessas áreas de políticas. Abrir a economia a capitais forâneos, privatizar setores econômicos importantes, reduzir gastos com funcionalismo público, sobretudo com inativos, e mudar o regime previdenciário geral requeriam, mais do que uma agenda governamental, uma agenda constitucional.
Diante desse obstáculo decisório, Collor iniciou suas reformas liberalizantes cinco anos antes numa área cujas medidas permitiam decisões por decreto do Executivo: a abertura comercial. As privatizações, impulsionadas em seu governo pela aprovação de uma lei ordinária (Programa Nacional de Desestatização, Lei no 8.031/1990), requeriam mudanças constitucionais para se aprofundar, devido a monopólios estatais definidos constitucionalmente. Isso se evidencia no conteúdo das emendas constitucionais apresentadas no Quadro 2, aprovadas no primeiro governo FHC. Note-se que todas dizem respeito à desregulamentação de setores do serviço público, à desestatização de monopólios, à abertura do mercado nacional a investidores estrangeiros, enfim, temas relacionados a uma certa política econômica - policy, não polity.

Particular atenção merece a Emenda $n^{\circ} 8$, referente às telecomunicações. Isso porque foi nesse setor que se verificou o maior volume de recursos oriundos de privatizações realizadas pelo governo federal. A tabela a seguir indica os montantes.

QUADRO 2

Emendas Constitucionais Aprovadas Referentes às Privatizações Brasil - 1995-96

\begin{tabular}{lll}
\hline Emenda no & Tema & Aprovada/Promulgada em
\end{tabular}

Permite concessão dos serviços estaduais 15 de agosto de 1995 de distribuição de gás canalizado.

6 Elimina distinção entre empresas nacionais 15 de agosto de 1995 e estrangeiras; permite exploração do subsolo por quaisquer empresas sediadas no país; proíbe regulamentação por MP de emendas constitucionais aprovadas após 1995, que tenham modificado a redação de artigos.

7 Permite a navegação de cabotagem por embarcações estrangeiras.

8 Permite a concessão a empresas privadas 15 de agosto de 1995 dos serviços de telecomunicações.

9 Fim do monopólio estatal do petróleo. 9 de novembro de 1995

13

Resseguros deixam de ser monopólio estatal, cabe ao Estado a regulação

21 de agosto de 1996 do setor. 


\begin{tabular}{lccc}
\hline \multicolumn{3}{c}{$\frac{\text { TABELA 1 }}{}$} & \\
\multicolumn{4}{c}{ Privatizações - Resultados Acumulados } \\
Brasil - 1991-2000 & \\
\hline Programa & Receita de & Dívidas & US $\$$ milhões \\
\hline Total & Venda & Transferidas & Geral \\
\hline Privatizações Federais & $\mathbf{7 8 . 4 9 7}$ & $\mathbf{1 8 . 0 7 6}$ & 96.573 \\
$\quad$ Telecomunicações & 50.763 & 11.326 & 62.089 \\
$\quad$ PND & 26.978 & 2.125 & 29.103 \\
Privatizações Estaduais & 23.785 & 9.201 & 32.986 \\
\hline
\end{tabular}

Fonte: BNDES, out. 2000.

As privatizações e concessões no setor de telecomunicações, necessárias à obtenção dessas receitas, apenas se tornaram possíveis após a aprovação da Emenda Constitucional $\mathrm{n}^{\circ} 8$ e da Lei $\mathrm{n}^{\circ} 9.472$ (Lei Geral de Telecomunicações), em julho de 1997, cuja aprovação, por sua vez, não teria sido possível sem a mudança constitucional. Por isso, as privatizações no setor ocorreram apenas a partir de 1998. Importante nisso é que a aprovação de uma legislação infraconstitucional para regulamentar o processo de privatizações das telecomunicações dependia da modificação prévia de dispositivos constitucionais. Isso porque a policy nessa área foi elevada à condição de letra constitucional. Vejamos o que dizia o texto constitucional original, modificado pela emenda $\mathrm{n}^{\circ} 8$ :

“Art. 21. Compete à União:

(...) XI - explorar, diretamente ou mediante concessão a empresas sob controle acionário estatal, os serviços telefônicos, telegráficos, de transmissão de dados e demais serviços públicos de telecomunicações, assegurada a prestação de serviços de informações por entidades de direito privado através da rede pública de telecomunicações explorada pela União;

XII - explorar, diretamente ou mediante autorização, concessão ou permissão:

a) os serviços de radiodifusão sonora, de sons e imagens e demais serviços de telecomunicações; (...)"

$\mathrm{O}$ texto passou a ter a seguinte redação:

“Art. 21. Compete à União:

(...) XI - explorar, diretamente ou mediante autorização, concessão ou permissão, os serviços de telecomunicações, nos termos da lei, que disporá sobre a organização dos serviços, a criação de um órgão regulador e outros aspectos institucionais;

XII - explorar, diretamente ou mediante autorização, concessão ou permissão: a) os serviços de radiodifusão sonora e de sons e imagens; (...)"

Não apenas deixou de ser imperativo constitucional a exploração exclusivamente estatal dos serviços de telecomunicações (particularmente de telefonia). Passou também ao nível infraconstitucional ("nos termos da lei") a forma de organização dos serviços. Com isso, além de abrir-se caminho constitucional à exploração privada desses serviços, desconstitucionalizou-se parcialmente um item de policy, pois, muito embora a Carta continue a tratar de telecomunicações, passou a fazê-lo de forma mais genérica, de modo que futuros governos e maiorias congressuais possam alterar mais facilmente as políticas no setor, não mais protegidas pelo quórum qualificado de três quintos.

O teor de política econômica das reformas constitucionais de FHC fica nítido se considerarmos o número de emendas sobre o assunto, aprovadas no período, em comparação àquelas especificamente relacionadas a questões institucionais - regras do jogo político competitivo - aprovadas em qualquer tempo (Gráfico 1).

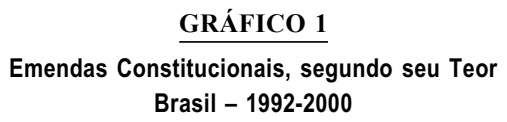

$\square$ Caráter eminentimente político

$\square$ Sociais

- Propósitos fiscais imediatos

目 Reforma de Estado

$\checkmark$ Desregulamentação da economia

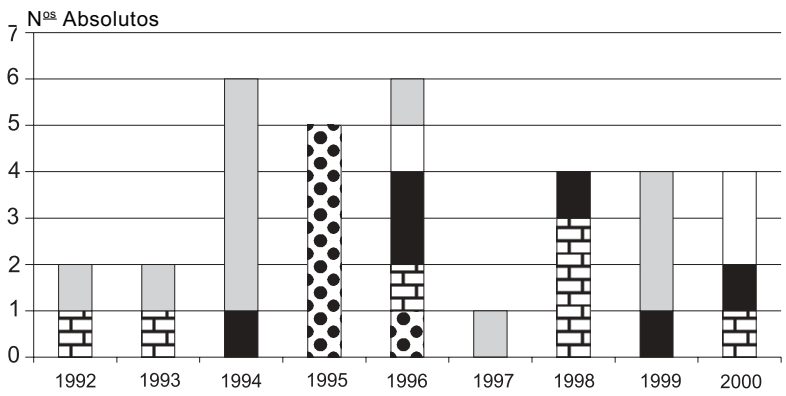

Fonte: Figueiredo e Limogi (1999).

Durante o primeiro mandato de FHC, apenas duas emendas cujo conteúdo diz respeito à organização da polity foram aprovadas: as de números 15 e 16, referentes respectivamente à criação de novos municípios e ao instituto da reeleição para cargos executivos. ${ }^{9}$ Quase todas as demais diziam respeito a questões de ordem econômica (13 emendas) e uma tratava de política social, a Emenda ${ }^{\circ}$ 
14, de 1996, que criou o Fundo de Desenvolvimento da Educação Fundamental. De qualquer forma, todas diziam respeito antes a policies que a polity. O Quadro 3 traz a relação de todas as emendas constitucionais aprovadas, dividindo-as em blocos segundo seu teor.

\section{QUADRO 3}

Blocos de Emendas Constitucionais e Respectivo Teor Brasil - 1992-2000

\begin{tabular}{ll}
\hline Emendas & \multicolumn{1}{c}{ Teor } \\
\hline $5,6,7,8,9$ e 13 & $\begin{array}{l}\text { desregulamentação e desestatização } \\
\text { da economia/efeitos fiscais indiretos }\end{array}$ \\
$1,3,11,18,19$ e 20 e 25 & $\begin{array}{l}\text { reforma do Estado/ } \\
\text { efeitos fiscais estruturais }\end{array}$ \\
$1-\mathrm{R}, 10,12,17,21$ e 27 & propósitos fiscais imediatos \\
$2,4,2-\mathrm{R}, 3-\mathrm{R}, 4-\mathrm{R}, 5-\mathrm{R}, 6-\mathrm{R}, 15,16$, & caráter eminentemente político \\
$22,23,24$ & \\
14,26 e 28 & sociais/efeitos fiscais indiretos \\
\hline
\end{tabular}

Em seu primeiro ano de governo, o presidente centrou fogo na mudança dos parâmetros da ordem econômica, pavimentando o caminho para as privatizações e a liberalização econômica. Aprovou cinco das seis emendas indicadas no Quadro 2, restando apenas uma, a de ${ }^{\circ} 13$, aprovada no ano seguinte. $O$ presidente contava então com certo fôlego na área fiscal, graças à aprovação, no ano anterior, da Emenda Constitucional de Revisão n ${ }^{\circ}$, que criou o Fundo Social de Emergência (FSE). Este, ao desvincular receitas de despesas e transferências definidas constitucionalmente, deu ao Executivo maior margem de manobra na execução orçamentária. O FSE foi prorrogado em 1996 por meio da emenda ${ }^{\circ} 10$, rebatizado como Fundo de Estabilização Fiscal (FEF). Além disso, o Executivo obteve nesse ano a aprovação de mais uma emenda constitucional com propósitos fiscais imediatos, a de $\mathrm{n}^{\circ} 12$, que criou a CPMF (Contribuição Provisória sobre Movimentação Financeira), nova denominação do IPMF (Imposto Provisório sobre Movimentação Financeira), também criado por meio de emenda constitucional, a de $\mathrm{n}^{\circ} 3$, de $1993 .^{10}$

A média de emendas constitucionais durante os dois governos FHC, até 2000, é de quatro por ano; somente no primeiro mandato foram aprovadas 16 . É um desempenho notável, sobretudo considerando-se que as exigências para a aprovação de emendas constitucionais são muito maiores se comparadas a leis - três quintos dos votos de deputados e senadores, em duas votações em ambas as Casas, sendo que qualquer modificação introduzida numa delas pelo que foi votado pela outra deve ser ratificada pela Casa que aprovou inicialmente o texto. A importância que tiveram as deliberações constitucionais no Congresso brasileiro durante o primeiro mandato de FHC ficam evidentes se compararmos duas grandezas. A primeira refere-se ao número de emendas aprovadas nesse período comparativamente ao período anterior (governos Collor e Itamar Franco). Após a promulgação da nova Carta (outubro de 1988), as primeiras emendas foram aprovadas em 1992, mas os projetos aprovados não foram de iniciativa do Executivo - uma dizia respeito à remuneração de parlamentares no plano subnacional e a outra regulamentava o plebiscito sobre sistema de governo, previsto na Carta para ocorrer em 1993. Nesse ano, duas novas emendas foram aprovadas, uma que contemplava um pacote de modificações constitucionais e outra que definia prazos para a legislação eleitoral. Apenas o conteúdo da primeira delas contemplava preocupações do governo - previdência do funcionalismo, sistema tributário, IPMF.

As seis emendas aprovadas em 1994 são um caso à parte: todas elas tratam de emendas constitucionais de revisão. A própria Carta previa a realização de uma revisão cinco anos após sua promulgação, em sessão unicameral do Congresso e aprovação das mudanças por maioria absoluta, não podendo o Executivo apresentar propostas, embora a emenda que criou o FSE fosse obviamente de seu interesse. As condições distintas de tramitação e o fato de tratar-se de uma revisão já prevista dão caráter muito peculiar a essas emendas, que não podem ser classificadas como as demais. Por isso, as seis emendas de 1994 devem ser vistas como uma excepcionalidade. ${ }^{11}$

A segunda grandeza a considerar é o número de votações nominais de caráter constitucional e não-constitucional realizadas na Câmara de Deputados nos dois períodos. Segundo levantamento de Figueiredo e Limongi (1999), foram 166 votações constitucionais nesses quatro anos contra apenas 11 durante os cinco anos precedentes, e 188 votações não-constitucionais contra 101 no período anterior. Ou seja, houve mais votações nominais apenas de tipo constitucional durante o primeiro governo FHC do que votações nominais de qualquer tipo no período anterior. Embora mesmo o desempenho medido pela quantidade de votações não-constitucionais seja bastante superior no período FHC - $86 \%$ das votações a mais e média de 41,5 votações nominais por ano, contra apenas 20,2 no período 
anterior -, é a apreciação de temas constitucionais que se destaca de forma notável - votam-se 15 vezes mais itens de teor constitucional nesse período do que no precedente. O Gráfico 2 deixa essa diferença evidente.

\section{GRÁFICO 2}

Votações Nominais Constitucionais e Não-Constitucionais Brasil - 1990-1999

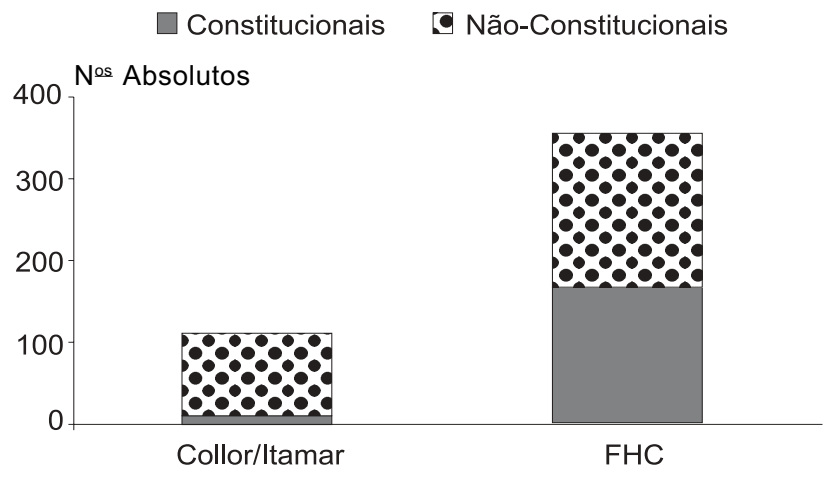

Fonte: Figueiredo e Limongi (1999).

Essa verdadeira agenda constituinte não deve, entretanto, ser vista isoladamente. Ela opera, na verdade, de forma articulada ao restante da produção normativa. Em primeiro lugar, como já indiquei para as telecomunicações, pelo fato de que parte da produção normativa infraconstitucional dependia de mudanças de caráter constitucional. Além da privatização da telefonia, também as políticas fiscais no plano infraconstitucional beneficiaram-se de decisões constituintes. A aprovação das medidas de efeito fiscal imediato (FSE/FEF/DRU e IPMF/CPMF) proporcionaram ao Executivo maior liberdade no manejo orçamentário, pois ao desvincular receitas proporcionaram folga orçamentária, permitindo limitar por decreto gastos públicos, facilitando a persecução das metas fiscais fixadas. Assim, a utilização na execução orçamentária de um mecanismo normativo exclusivo do Executivo (o decreto) ganhou maior efetividade com a aprovação de medidas fiscais constitucionais - para as quais requer-se negociar mais, contar com mais apoio parlamentar e superar obstáculos institucionais maiores, pois há um maior número de veto players a dificultar o processamento das decisões.

O segundo ponto importante para esta discussão é apontar que o encaminhamento da agenda constituinte no Congresso beneficiou-se da desobstrução da pauta de negociações entre os dois poderes pela delegação ao Executivo de capacidade legislativa mediante a reedição de medidas provisórias. Passando ao presidente a atribuição de decidir de forma autônoma sobre parte da produção legal, o Congresso viu-se mais à vontade para encaminhar os trabalhos referentes às deliberações de caráter constitucional. Assim, duas agendas operaram de forma articulada: uma, constituinte e ultraconsociativa - a das reformas constitucionais. Outra, delegativa e majoritária - a das medidas provisórias reeditadas. Observe-se que a delegação propriamente dita aplica-se ao caso da reedição de MPs, não às edições originárias. Editar MPs é prerrogativa constitucional do Executivo, podendo ocorrer com ou sem anuência do Congresso, ou seja, independentemente de haver delegação, ou de o Executivo contar com maioria parlamentar. Reeditar MPs depende da anuência parlamentar, tácita ou explícita, pois apenas se reeditam MPs que não tenham sido apreciadas pelo Legislativo. Assim, caso não queira delegar poderes legislativos ao Executivo consentindo reedições, basta ao Parlamento apreciar as MPs editadas originariamente.

A delegação mostrou-se útil aos dois poderes não só por conferir maior eficácia decisória à implementação da agenda de governo levada a cabo por meio das MPs editadas e reeditadas, mas também por transbordar esse ganho de eficácia à agenda constitucional, que ganhou mais espaço na pauta de negociações entre os dois poderes. Se toda a legislação implementada e mantida por MPs tivesse de ser também apreciada pelo Congresso, tornar-se-ia mais extensa essa pauta e, conseqüentemente, mais custosa e de encaminhamento mais vagaroso. Com a delegação, a manifestação do Congresso sobre as MPs somente se processaria caso alguma medida indesejada pelos parlamentares fosse expedida. Nesse caso, um mecanismo de "alarme de incêndio" poderia mostrar-se suficiente para garantir que a delegação não redundasse numa perda de agenciamento (Amorim e Tafner, 1999; Kiewiet e McCubbins, 1991).

Havendo delegação, não há usurpação das prerrogativas parlamentares pelo Executivo. Trata-se de uma escolha feita por aqueles que detêm o controle do Congresso - as maiorias e as mesas diretoras, situacionistas durante todo o governo de FHC. A mesma coalizão parlamentar que permitiu ao governo mudar a Constituição optou por delegar-lhe poder legislativo mediante a reedição de MPs. Se, todavia, é razoável expedir novamente uma MP, 30 dias após sua primeira edição, caso as razões "urgentes" que a motivaram permaneçam (como entendeu o STF no julgamento dessa questão), que dizer das MPs sucessiva- 
mente reeditadas, algumas delas por vários anos? Perde sentido a noção de provisoriedade, pois uma medida provisória mantida por longo tempo equivale a uma lei vigente por esse mesmo período. Uma lei sui generis, aprimorável mediante pequenas alterações sempre que aprouver ao Executivo.

A prática acarreta prejuízos à democracia, por três razões. Primeiro, por retirar da principal arena de debates sobre questões nacionais - o Congresso - a discussão sobre decisões importantes para o país. Quando o Executivo decide sozinho, qualquer questionamento às decisões é possível apenas após elas começarem a surtir efeitos, desvalorizando os debates que depois venham a ocorrer. Em segundo lugar, porque a persistência dessa prática ao longo de alguns anos pode perpetuá-la, conformando um sistema político com um debate parlamentar débil sobre temas não só relevantes como também urgentes. A terceira razão é a questionável constitucionalidade de parte das reedições, uma vez entendidas como decorrentes de uma delegação legislativa.

$\mathrm{Na}$ Constituição brasileira, apenas a lei delegada é instrumento de delegação legislativa. Trata-se de recurso institucional parcamente usado: desde janeiro de 1946, foram expedidas apenas 13 leis delegadas, 11 delas sob a Constituição de 1946, antes do regime militar (até 1962). Após 1988, promulgaram-se apenas duas, durante o governo Collor. Ironicamente, ambas foram modificadas ou regulamentadas por medidas provisórias. Há, porém, uma série de limitações ao seu uso, pois não podem ser objeto de delegação "os atos de competência exclusiva do Congresso Nacional, os de competência privativa da Câmara dos Deputados ou do Senado Federal, a matéria reservada à lei complementar, nem a legislação sobre a organização do Poder Judiciário e do Ministério Público, a carreira e a garantia de seus membros; nacionalidade, cidadania, direitos individuais, políticos e eleitorais; planos plurianuais, diretrizes orçamentárias e orçamentos" (art. 68).

Como não há para as MPs limitações quanto ao tema tratado, tem sido praxe sua edição e reedição para legislar sobre matéria orçamentária. Seu uso para modificar a Lei de Diretrizes Orçamentárias (LDO) é prática corrente desde o governo Itamar Franco. A MP n ${ }^{\circ} 1.287$, de janeiro de 1996, que modificava a LDO válida para aquele ano, foi reeditada por três vezes, sem modificações importantes até maio, quando finalmente o novo Orçamento foi sancionado. Dois dias depois da sanção, a mesma MP, que acabou sendo parâmetro para a confecção do Orçamento (já que modificava a LDO), foi novamente reeditada, dessa vez introduzindo modificações noutro artigo da lei. Notese bem: a LDO, feita para "orientar a elaboração da lei orçamentária anual" (art. 165), passou a sofrer modificações mediante medidas provisórias depois da votação e sanção do próprio orçamento! A partir de setembro daquele ano, outro artigo da lei foi modificado por MP e, a partir de outubro, as novas reedições (então $\mathrm{MP} \mathrm{n}^{\circ} 1.525$ ) passaram a incluir modificações da LDO para 1997 - votada pelo Congresso e sancionada pelo presidente apenas três meses antes -, além de alterações de outros artigos da LDO para 1996. Essa MP continuou a ser reeditada, tendo ultrapassado 60 reedições até ser transformada na Lei ${ }^{\circ} 10.210$ de março de 2001.

Ora, se não pode o Congresso, por decisão explícita de sua maioria, mediante a lei delegada, transferir poderes legislativos ao presidente em matéria orçamentária, poderia fazê-lo de forma tácita, não apreciando medidas provisórias que serão fatalmente reeditadas pelo Executivo? Ainda que as decisões do STF não se reportem à idéia de delegação legislativa efetivada por meio da reedição de MPs, não é isso o que ocorre? Creio haver uma incongruência político-constitucional na reedição de MPs acerca de política orçamentária, mesmo que talvez não se verifique do ponto de vista jurídico-constitucional (formal), já que o próprio STF não reconhece na reedição de medidas provisórias uma forma de delegação. Se a intenção dos constituintes era não permitir delegação em certos casos, e ela de fato ocorre aqui, há claro desrespeito ao espírito da Carta. Segundo Ferreira Filho (1995:264, grifos meus): "Tal poder é condicionado pela ocorrência de relevância e urgência. Não tem ele limitação explícita quanto à matéria. Entretanto, pela lógica, de seu campo hão de ser excluídas as matérias de competência exclusiva do Congresso Nacional, ou de suas casas, ou outras submetidas a leis complementares, ou aquelas em que é proibida a delegação. Em todos esses casos, nitidamente, a Constituição reserva às Câmaras a deliberação. Igualmente escapam ao alcance das medidas provisórias as matérias de iniciativa reservada dos tribunais".

Os prejuízos à democracia brasileira serão mais graves caso a reedição continuada de MPs se converta num padrão. A Tabela 2 e o Gráfico 3 parecem indicar isso. A reedição de MPs aumenta contínua e avassaladoramente. Pode-se observar que praticamente não há mais medidas provisórias rejeitadas pelo Congresso desde o governo Itamar Franco e também se reduziu muito o volume de MPs convertidas em lei - ou seja, o Parlamento desobrigou-se da sua tarefa de apreciar esses atos do Executivo. 
TABELA 2

Medidas Provisórias - Edição e Reedição, segundo Governo Brasil - 1988-2001

\begin{tabular}{lrrrrrr}
\hline Governo & Sarney & Collor & Itamar & FHC (I) & FHC (II) & Total \\
\hline Originárias & 125 & 87 & 141 & 160 & 79 & 592 \\
Reeditadas & 22 & 73 & 364 & $(1) 2.449$ & $(2) 2.419$ & 5.327 \\
Convertidas & 109 & 66 & 118 & 82 & 85 & 463 \\
Revogadas & 2 & 5 & 5 & 11 & 5 & 28 \\
Sem Eficácia & 5 & 5 & 15 & 3 & 1 & 29 \\
Rejeitadas & 9 & 11 & - & 1 & 1 & 22 \\
Em Tramitação & - & - & - & 38 & 11 & 49 \\
Editadas & 147 & 160 & 505 & 2.609 & 2.498 & 5.919
\end{tabular}

Fonte: Presidência da República. Subchefia para Assuntos Jurídicos. Atualizado em 18/06/2001. (1) Inclui 699 reedições de medidas originárias de governos anteriores.

(2) Inclui 137 reedições de medidas originárias de governos anteriores.

O número de reedições cresce imensamente durante os governos FHC. Embora já tivesse superado o número de edições originárias durante o governo Itamar, passa então a superá-lo por larguíssima margem. Junto ao crescimento do número de reedições, vem a redução das medidas apreciadas pelo Congresso, proporcionalmente às originárias. No período Sarney, as medidas apreciadas (convertidas ou rejeitadas) correspondiam a $94,4 \%$ das editadas originalmente; no período Collor, há queda nessa proporção, mas o número das apreciadas se mantém elevado $(88,5 \%)$. Essa variação pode ser explicada parcialmente pelo aumento na proporção das MPs revogadas ou que perderam eficácia nesse período $(11,5 \%$ contra $5,6 \%$ no período Sarney um percentual de aumento exatamente igual ao da diminuição das apreciações). No período Itamar Franco, as apreciações reduzem-se um pouco mais em relação às edições originais - caem para $83,7 \%$ - e as revogadas e sem eficácia também têm pequena redução - caem para 9,9\%. $\mathrm{O}$ que realmente aumentou nesse período foram as reedições: saltam de uma relação de 0,176 reedição por edição no governo Sarney e de 0,839 no período Collor para 2,58 reedições por edição no período Itamar.

Os índices explodem nos governos de Fernando Henrique. Em seu primeiro mandato, as apreciações caem para apenas $51,9 \%$, as revogadas e sem eficácia caem para $8,75 \%$ e a relação entre reedições e edições originárias salta para 15,3 por 1 , (10,9 por 1 , considerando apenas reedições de medidas editadas durante o próprio governo FHC). No segundo mandato, até o momento em que escrevo, a última relação saltou para 30,6 por 1 (27,03 por 1, considerando apenas as MPs editadas pelo próprio FHC). O gráfico a seguir ilustra de forma mais visível os dados da tabela.

\section{GRÁFICO 3}

Medidas Provisórias - Situação em Vários Governos

Brasil - 1998-2000
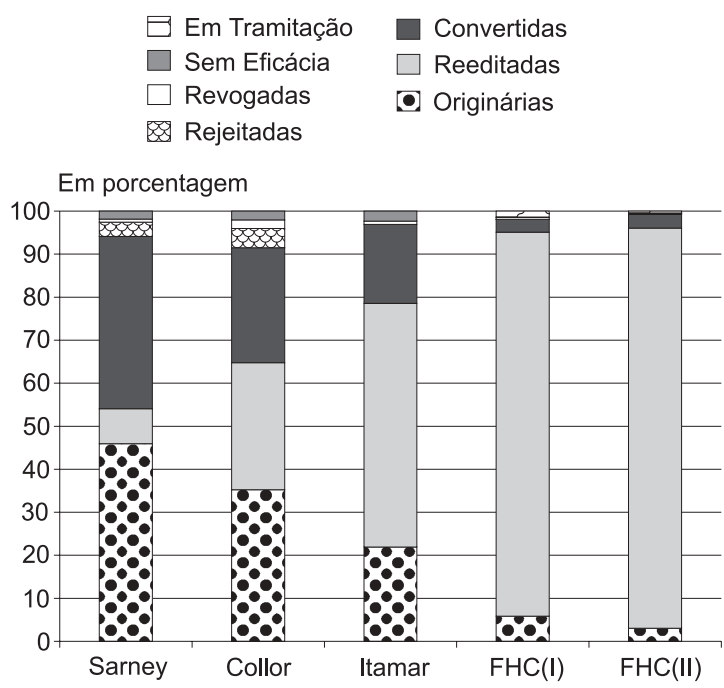

Fonte: Presidência da República. Subchefia para Assuntos Juridicos. Atualizado em 18/06/2001.

\section{CONCLUSÃO}

Como vimos, o encaminhamento de uma agenda constituinte é característica importante do período Fernando Henrique Cardoso. Devido às peculiaridades do projeto governamental desse presidente, essa agenda tornou-se impositiva, já que a Carta de 1988 constitucionalizou diversas matérias que podem ser caracterizadas antes como policies que como polity. A distinção pode ser feita claramente se considerarmos dois critérios: primeiro, polity diz respeito a regras fundamentais do jogo político, à estruturação do Estado, e não ao conteúdo de decisões que o governo gera corriqueiramente; segundo, são policies todas as decisões cuja transformação é passível de mudança, dependendo do grupo político que vier a tornar-se majoritário como fruto das disputas democráticas. Noutras palavras, é policy o que puder ser classificado como plano de governo e cuja implementação não colocar em risco a preservação da polity.

O presidente FHC foi bem-sucedido no encaminhamento dessa agenda. Aprovou todas as iniciativas relacionadas à reforma da ordem econômica, abrindo caminho à privatização; obteve do Congresso cinco emendas constitucionais que lhe permitiram alívio fiscal (fora a emenda do FSE, herdada da revisão constitucional de 1994); obteve vitórias na reforma do Estado, aprovando cinco emendas, duas delas particularmente importantes - reformas 
administrativa e da previdência - apesar das queixas de que ficaram aquém do pretendido; isso sem falar na importantíssima emenda da reeleição, que garantiu a Fernando Henrique um segundo mandato e, assim, mais fôlego e tempo para dar continuidade à sua agenda reformista e de estabilização.

As emendas referentes à ordem econômica tornaram o texto constitucional mais genérico, remetendo à legislação - à normatividade infraconstitucional, portanto - muito do que podemos classificar como policies. Basicamente, retiraram do texto itens que tornavam obrigatória uma política econômica nacionalista e estatista. Futuros governos poderão atuar mais facilmente nessas áreas, desde que obtenham maiorias parlamentares que não mais precisarão ser de três quintos. As emendas geradoras de ganhos fiscais de curto prazo são todas provisórias, alterando por pouco tempo (ainda que o tenham feito reiteradamente nos últimos anos) a distribuição de recursos públicos. Por quebrarem vinculações constitucionais de receitas a transferências para governos subnacionais e gastos na área social, exigiam a modificação da Carta.

As emendas da reforma do Estado modificaram policies contidas na Carta, mas de uma forma distinta das que trataram da ordem econômica. Mais que remeter regulamentações ao plano infraconstitucional, mantiveram-se detalhistas. A emenda da reforma administrativa, por exemplo, chega a especificar o cálculo da indenização de funcionários demitidos. Dessa forma, para atuar nessas áreas, e implementar policies que contrariem o texto constitucional reformado, futuros governos terão de reunir novamente quórum qualificado no Congresso. $\mathrm{O}$ fato de transformações referentes à previdência e à administração pública terem sido menores que as pretendidas pelo Executivo significa, na verdade, que se manteve muito do que os constituintes de 1987-1988 haviam criado. Assim, mais do que o governo FHC e sua base parlamentar, são aqueles constituintes que estão ainda a limitar o raio de ação de futuros governos e, portanto, de futuras maiorias saídas das urnas.

Limitar os governos é uma das funções de textos constitucionais. Criam-se restrições e comprometimentos para evitar que maiorias eventuais ou governantes audazes restrinjam liberdades cidadãs, espezinhem direitos, oprimam minorias. Mas cabe questionar, diante do caso brasileiro, se essas restrições prévias devem valer indistintamente para policies e polity. Restringir estruturalmente vontades majoritárias ocasionais, conjunturais, é limitar a capacidade de efetivação da vontade do demos. Que a limitação se dê tendo em vista a preservação da polity poliárquica é uma condição da continuidade do próprio jogo em que o demos influi nas decisões de governo, viabilizando uma exigência democrática: a de que minorias possam tornar-se maiorias, ciclicamente. Mas se decisões de governo, policies, são elas próprias congeladas por eventuais maiorias (mesmo que dilatadas), estaríamos novamente restringindo liberdade, tornando estrutural o que, por natureza, deveria ser conjuntural numa democracia. É decisão democrática atar futuros governos a uma agenda constituinte?

A mesma maioria que permitiu ao governo Fernando Henrique mudar o texto constitucional delegou-lhe poderes legislativos mediante a anuência à reedição de MPs. Por isso mesmo, o padrão delegativo aqui descrito, mais que um momento da politics, é política de governo, policy, e a responsabilidade por ela cabe aos governantes de plantão - sejam membros do Legislativo ou do Executivo. A opção por essa política gera grande incerteza jurídica, pois boa parte das leis em vigor são, na verdade, medidas provisórias, revogáveis e modificáveis a qualquer tempo, requerendo renovação mensal. Torna-se difícil prever com razoável acerto o modo como o país será governado no curto e médio prazos, prejudicando não só a democracia, mas também o desenvolvimento econômico, por gerar algo que o mercado repudia: incerteza quanto às regras do jogo. Algo que deveria ser estrutural - o arcabouço legal - oscila ao sabor das conjunturas. ${ }^{12}$

\section{NOTAS}

E-mail do autor: claudio.couto@uol.com.br

1. Em sua discussão, Sartori lança mão de uma versão modificada do debate acerca dos custos da tomada de decisão e dos custos externos da decisão feita por Buchanan e Tullock (1999 [1962]).

2. Para discussão sobre este ponto, ver a introdução e os capítulos da primeira parte do livro organizado por Przeworski, Stokes e Manin (1999).

3. Como aponta Schumpeter (1984:355), os eleitores escolhem aqueles que irão governá-los, não as políticas que irão implementar: "Democracia significa apenas que o povo tem a oportunidade de aceitar ou recusar as pessoas designadas para governá-lo". Embora seja possível ao eleitor estipular inequivocamente quem agirá em seu nome, é possível que o escolhido não aja da maneira prevista, podendo ser "traída" a delegação eleitoral (perda de agenciamento).

4. Afinal, é possível que as preferências eleitorais majoritárias num dado momento contrariem princípios constitucionais. Estes, então, funcionam como salvaguardas de caráter permanente, não importando quais vontades prevaleçam ocasionalmente.

5. Isto talvez ajude a compreender a importância que podem ter regras de transição em processos de modificação constitucional ou de normas paraconstitucionais. O caráter paulatino de certas mudanças da polity pode ser coerente com a própria idéia de polity. Assim, não apenas não se modifica a polity fácil e freqüentemente, mas também, 
quando esta é modificada, os atores políticos devem ter tempo para se preparar para a modificação.

6. Certas garantias fundamentais, como o direito de propriedade, podem ser incluídas neste caso. Apesar de esse direito poder ser enquadrado na condição de uma política substantiva, mais do que uma regra do jogo, sua importância numa sociedade capitalista é de tal monta que se torna imperativo protegê-lo - impondo limites a decisões governamentais que venham a afetá-lo -, caso não se queira pôr em risco a própria continuidade do jogo democrático. $\mathrm{O}$ que se nota aqui é a importância do alcance das decisões numa democracia, fator notado por Schumpeter (1984:363-4) como condição para a própria sobrevivência do regime democrático.

7. A exigência de quóruns parlamentares qualificados para a aprovação de normas que digam respeito a questões lingüísticas por exemplo, pode ser despropositada num país uniforme sob esse aspecto, mas fará sentido num país multilingüístico e no qual essa dimensão da vida social seja politicamente relevante.

8. A distinção entre lei e norma constitucional insere-se neste quadro. A segunda é superior à primeira, tanto que o ramo do poder responsável pela formulação legislativa não se deveria incumbir também da normatização constitucional, já que esta parametriza o próprio legislar. São, contudo, normalmente previstas condições para a modificação dessa normatividade pelo legislador, contudo em caráter excepcional, sendo os trâmites muito mais exigentes que os do processo legislativo ordinário. Ackerman (1988:163), com base nos Federalistas, estabelece uma distinção entre política normal e política constitucional. Nesta segunda se daria de forma efetiva a relação de representação entre o cidadão e aquele que toma as decisões. Diz ele: "Embora a política constitucional seja o gênero mais elevado de política, ela apenas deve dominar a vida da nação durante raros períodos de elevada consciência política. Durante os longos períodos que entremeiam estes momentos constitucionais, uma segunda forma de atividade - que chamarei de política normal - prevalece. Aqui, as facções tentam manipular as formas constitucionais da vida política para perseguir apenas os seus próprios e estreitos interesses. A política normal precisa ser tolerada em nome da liberdade individual; ela é, contudo, democraticamente inferior à intermitente e irregular política da virtude pública, associada aos momentos de criação constitucional".

9. É importante chamar a atenção para o fato de que mesmo a emenda referente à criação de municípios tinha implicações econômicas, no caso, fiscais, já que a multiplicação de municipalidades tinha como conseqüência uma distribuição menos eficiente dos recursos do Fundo de Participação dos Municípios.

10. Esta é uma emenda constitucional de difícil classificação, pois se tratava de um pacote de mudanças constitucionais de diversos tipos. Como preponderavam questões relacionadas a mudanças do desenho do Estado em termos de sua organização administrativa, optei por classificá-la no Quadro 3 e no Gráfico 1, dentro do bloco de emendas relacionadas à reforma do Estado.

11. Para uma excelente discussão acerca do processo de revisão constitucional, ver o trabalho de Melo (1996).

12. No momento em que concluo a redação deste artigo, a Câmara de Deputados acaba de aprovar um projeto de emenda constitucional que limita a possibilidade de reedição de MPs, além de restringir também o leque de temas passíveis de normatização por esse instrumento. $\mathrm{O}$ projeto ainda deverá seguir para o Senado.

\section{REFERÊNCIAS BIBLIOGRÁFICAS}

ACKERMAN, B. “Neo-federalism?”. In: ELSTER, J. e SLAGSTAD, R. (eds.). Constitutionalism and democracy. Cambridge, Cambridge University Press, 1988.

ALMEIDA, M.H.T. "Pragmatismo por necessidade: os rumos da reforma econômica no Brasil". Dados. Rio de Janeiro, Iuperj, v.39, n.2, 1996.
AMORIM NETO, O. e TAFNER, P. "O Congresso e as medidas provisórias: delegação, coordenação e conflito". Rio de Janeiro, Iuperj, 1999, mimeo.

BUCHANAN, J.M. e TULLOCK, G. The calculus of consent: logical foundations of constitutional democracy. Indianapolis, Liberty Fund, 1999 [1962].

COUTO, C.G. O desafio de ser governo: o PT na Prefeitura de São Paulo (1989-1992). Rio de Janeiro, Paz e Terra, 1995.

"Governabilidade e reforma do Estado". O Estado de S.Paulo, 28/11/1996, p.A-2.

"A agenda constituinte e a difícil governabilidade". Lua Nova. São Paulo, Cedec, n.39, 1997.

"A longa constituinte: reforma do Estado e fluidez institucional no Brasil". Dados. Rio de Janeiro, Iuperj, v.41, n.1, 1998 a.

"Os mecanismos do ajuste: instituições e agendas na política econômica", texto apresentado ao Grupo Temático Estado e Políticas Públicas, dentro do I Encontro da Associação Brasileira de Ciência Política (ABCP). Rio de Janeiro, 18/12/1998b.

DAHL, R.A. Poliarquia: participação e oposição. São Paulo, Edusp, 1997.

FERREIRA FILHO, M.G. Do processo legislativo. $3^{\mathrm{a}}$ ed. atualizada. São Paulo, Saraiva, 1995.

FIGUEIREDO, A. e LIMONGI, F. "O Congresso e as medidas provisórias: abdicação ou delegação?". Novos Estudos. São Paulo, Cebrap, n.47, mar. 1997.

Executivo e Legislativo na nova ordem constitucional. Rio de Janeiro, Ed. FGV; São Paulo, Fapesp, 1999.

HAGGARD, S. e KAUFMAN, R. "O Estado no início e na consolidação da reforma orientada para o mercado". In: SOLA, L. (org.). Estado, mercado e democracia: política e economia comparadas. Rio de Janeiro, Paz e Terra, 1993.

HELD, D. "Democracia, o Estado-Nação e o sistema global". Lua Nova. São Paulo, Cedec, n.23, mar. 1991.

KIEWIET, D.R. e McCUBBINS, M. The logic of delegation: congressional parties and the appropriations process. Chicago and London: Chicago University Press, 1991.

LIJPHART, A. As democracias contemporâneas. Lisboa, Gradiva, 1989.

MELO, M.A. "O jogo das regras: a política da reforma constitucional, 1993-1996". Trabalho apresentado ao XX Encontro Anual da Anpocs. Caxambu, out. 1996.

PESSANHA, C. "A delegação legislativa no Brasil: o decreto-lei e a medida provisória, 1965-1998". A ousadia critica: ensaios para Gabriel Cohn. Londrina, Ed. UEL, 1998.

PRZEWORSKI, A.; STOKES, S.C. e MANIN, B. (orgs.). Democracy, accountability, and representation. Cambridge, Cambridge University Press, 1999.

SALLUM Jr., B. e KUGELMAS, E. "O Leviatã acorrentado: a crise brasileira dos anos 80". In: SOLA, L. (org.). Estado, mercado e democracia: política e economia comparadas. Rio de Janeiro, Paz e Terra, 1993.

SARTORI, G. A teoria da democracia revisitada, 2 vols. São Paulo, Ática, 1994.

SCHUMPETER, J.A. Capitalismo, socialismo e democracia. Rio de Janeiro, Zahar, 1984.

TSEBELIS, G. "Processo decisório em sistemas políticos: veto players no presidencialismo, parlamentarismo, multicameralismo e pluripartidarismo". Revista Brasileira de Ciências Sociais, v.12, n.34, 1997.

WHITEHEAD, L. "On 'reform of State', and 'regulation of the market". World Development, special issue, v.21, n.8, 1993. 